Mini Review

\section{Angiotensin II type 1 receptor and the activation of Myosin Light-Chain Kinase and Protein Kinase C- $\beta$ II: Mini Review}

\author{
Gerry A Smith* \\ University of Cambridge, 14, Lantree Cres. Trumpington, Cambridge CB2 9NJ, UK
}

\section{Summary}

The involvement of the angiotensin II type 1 receptor in the Frank-Starling Law of the Heart, where the various activations are very limited, allows simple analysis of the kinase systems involved and thence extrapolation of the mechanism to that of angiotensin control of activation of cardiac and skeletal muscle contraction. The involvement of phosphorylation of the myosin light chain in the control of contraction is accepted but not fully understood. The involvement of troponin-I phosphorylation is also indicated but of unknown mechanism. There is no known signal for activation of myosin light chain kinase or Protein Kinase $\mathrm{C}-\beta \mathrm{ll}$ other than $\mathrm{Ca}^{2+} /{ }_{\text {calmodulin }}$ but the former is constitutively active and thus has to be under control of a regulated inhibitor, the latter kinase may also be the same. $\mathrm{Ca}^{2+} /$ calmodulin is not activated in Frank-Starling, i.e. there are no diastolic or systolic $\left[\mathrm{Ca}^{2+}\right]$ changes. I suggest here that the regulated inhibition is by myosin light chain phosphatase and/or $\beta$-arrestin. Angiotensin activation, not involving $G$ proteins. is by translocation of the $\beta$-arrestin from the sarcoplasm to the plasma membrane thus reducing its kinase inhibition action in the sarcoplasm. This reduced inhibition has been wrongly attributed to a mythical downstream agonist property of $\beta$-arrestin.

\section{More Information}

*Address for Correspondence: Gerry A Smith, University of Cambridge, 14, Lantree Cres. Trumpington, Cambridge CB2 9NJ, UK, Tel: 44 1223 515394; Email: gas1000@cam.ac.uk

Submitted: 26 January 2020

Approved: 16 February 2020

Published: 17 February 2020

How to cite this article: Smith GA. Angiotensin II type 1 receptor and the activation of Myosin Light-Chain Kinase and Protein Kinase C- $\beta$ II: Mini Review. J Cardiol Cardiovasc Med. 2020; 5: 024-028.

DOI: 10.29328/journal.jccm.1001081

\section{ORCiD: orcid.org/0000-0002-3959-3523}

Copyright: @ 2020 Smith GA. This is an open access article distributed under the Creative Commons Attribution License, which permits unrestricted use, distribution, and reproduction in any medium, provided the original work is properly cited.

Keywords: Frank-Starling; angiotensin receptor; muscle contraction; myosin light chain kinase; Protein Kinase C- $\beta$ II; myosin light chain phosphatase; $\beta$-arrestin; myosin bound MgATP $\rightleftharpoons$ MgADP-phosphomyosin equilibrium; myosin $\mathrm{LC}$ affinity for $\mathrm{Ca}^{2+}$.

Check for updates

OPEN ACCESS

\section{Frank-starling law of the heart}

It will seem strange to initiate this study with the following full consideration of the Frank-Starling law of the Heart (FSLH). FSLH is an increase in contraction with increased ventricular filling, i.e. increase in contraction on increase in myofibril length in diastole. The involvement of secondary factors on myocyte length increase activation is very limited allowing correct attribution of functions. For example Van der Velden, et al. [1], suggest that sarcomere length dependence of calcium sensitivity and the effects of phosphorylation by protein kinase A (PKA) of troponin-I (cTn-I) and myosin binding protein-C (MyBP-C) are independent. Steinberg [2] reports that protein kinase C (PKC) activation via $\mathrm{Ca}^{2+} /$ calmodulin would reduce contractile strength and no changes in lipid based activators are reported on stretch. Supporting this Chandra, et al. [3] report that PKA phosphorylation has a negative effect on $\mathrm{Ca}^{2+}$ sensitivity but they get mixed up with the weak binding of $\mathrm{Mg}^{2+}$ to the troponins which has absolutely no effect on the activation of the cross-bridge. Kobayashi [4] also reports minimal effects of mimics of PKC phosphorylation of cardiac troponin-I (cTn-I). Neither of the common PKA or PKC take part in FSLH.

\section{The chemistry of contraction}

My recent study [5] of the mechanism of FSLH led me to reconsider the $\mathrm{Ca}^{2+}$ cooperativity of contraction of an unperturbed heart [6] and its inhibition [7] by $\mathrm{Mg}^{2+}$. The conclusion of this was that the cross-bridge ATPase is dependent on $\mathrm{Ca}^{2+}$ binding at two sites. In normal muscle the cross-bridge is restricted by myosin binding protein- $\mathrm{C}$ (MyBP-C) to only use CaATP as apparent substrate, i.e. the myosin-ATP bound $\mathrm{Mg}^{2+}$ has to be exchanged with $\mathrm{Ca}^{2+}$ for the cross-bridge to function. The consequential rate limiting step defined by Lionne [8] and Lymn [9] is release of phosphate which indicates phosphate is initially reversibly transferred to the myosin light chain.

\section{MgATP-myosin $\rightleftharpoons$ MgADP-phosphomyosin}

The exchange of $\mathrm{Mg}^{2+}$ for $\mathrm{Ca}^{2+}$ follows.

$\mathrm{Ca}^{2+}+\mathrm{MgADP}-$ phosphomyosin $\rightleftharpoons$ CaADP-phosphomyosin $+\mathrm{Mg}^{2+}$

The lever arm action follows and back to the resting state on binding MgATP. 


\section{CaADP-phosphomyosin $\rightleftharpoons$ CaADP-myosin $+\mathrm{Pi}$ \\ MgATP + CaADP-myosin $\rightleftharpoons$ MgATP-myosin + CaADP}

The phosphate $(\mathrm{Pi})$ release may be dependent on the MgATP binding.

The requirement of both the exchange of $\mathrm{Ca}^{2+}$ for $\mathrm{Mg}^{2+}$ and the cross-bridge initiation by $\mathrm{Ca}^{2+}$ binding to troponin- $\mathrm{C}$ (Tn-C) $[10,11]$ makes the $\mathrm{Ca}^{2+}$ activation of the cross-bridge cooperative [5] i.e. the Hill coefficient for $\mathrm{Ca}^{2+}$ activation is 2 .

\section{The limits to effectors in FSLH}

With the length induced contraction increase there is no associated decrease in the Hill coefficient and the shift of sensitivity to lower $\left[\mathrm{Ca}^{2+}\right]$ is positive but relatively small [2]. This is converse to the situation where the $\mathrm{Ca}^{2+}$ restricting function of MyBP-C breaks down, as occurs in hypertrophic cardiomyopathy [6], with mostly mutations of MyBP-C. Similar loss of its function is found on inhibition MyBP-C binding to the heavy chain by a specific fragment of its binding domain reported by Kampourakis [12] or on reversible removal of MyBP-C by Hofmann [13].

As there is no change in the $\mathrm{Ca}^{2+}$ cooperativity, Hill coefficient, the length induced shift to lower $\left[\mathrm{Ca}^{2+}\right]$ activation is simply the result of raising the effective $\mathrm{Ca}^{2+}$ affinity of either the cTn-C or the MgADP-phosphomyosin [5,6,8,9]. A recent study by Zhang, et al. [14], with structural sensitive probes indicates that it is changes in the myosin head region, myosin light chain 2 (MLC2), that are responsible for the stretch induced amplification of maximal tension. Thus it is not the thin filament cTn-C $\mathrm{Ca}^{2+}$ affinity but the increase in MgADP-phosphomyosin affinity for $\mathrm{Ca}^{2+}$ that is key to length induced activation. They also report that minimal changes in the thin filament structure occur giving a very small increase in $\mathrm{Ca}^{2+}$ sensitivity.

\section{The involvement of kinases}

de Tombe [15] and Akella [16] point out that the presence of both cTn-I and cTn-C together is a requisite for cardiac length induced activation, cTn-I is possibly a substrate for MLCK action. In FSLH cTn-I is not a substrate [1-4], for common PKA or PKC. The role of the antiparallel association of cTn-I and cTn-C has been investigated [3] in adrenergic stimulation, with PKA, but not the cTn-I phosphorylation on the threonine at residue 144 . Only the threonine at position 144 in cardiac TnI is essential for length induced increase in contraction. Phosphorylation of the tail end serines is not involved in FSLH. This was shown by Tachampa, et al. [17] by substituting a hybrid skeletal Tn-I, with or without the serines, with added threonine at residue 144. Furthermore PKA phosphorylation of the tail end serines [3] reduces $\mathrm{Ca}^{2+}$ sensitivity. Walker, et al. [18], using protein kinase C- $\beta$ II (PKC- $\beta$ II), an atypical PKC, have shown that phosphorylation of cTn-I on threonine 144 does increase the $\mathrm{Ca}^{2+}$ sensitivity of contraction. They also demonstrate that sensitivity to $\mathrm{Ca}^{2+}$ on MLCK action with $\mathrm{Ca} /$ calmodulin is independent of cTn-I modification, possibly swamped by MLC2 phosphorylation increase with calmodulin. PKC- $\beta$ II has been shown to bind to the thin filament [19] on activation by phorbol ester where it could phosphorylate the cTn-I. However no evidence of diglyceride level change has been shown on length increase of the myocyte. If PKC- $\beta I$ I is involved it most probably is; (a) in the sarcoplasm, (b) is constitutively active for cTn-I and (c) is hindered by the kinase inhibitor $\beta$-arrestin as is MLCK, vide infra.

It is extremely likely that the phosphorylation targets of MLCK are much altered when bound to calmodulin, as are those of PKC- $\beta$ II, in vivo it is accompanied by a calmodulin binding protein of unknown function. Demonstration of direct, uncatalyzed by calmodulin, phosphorylation by MLCK is lacking but this kinase is constitutively active and must occur when not inhibited. In FSLH there is no change in the level of adrenalin activation hence not $\mathrm{Ca}$ /Calmodulin action.

\section{The involvement of angiotensin}

By the use of knock-out mice the misnamed "multifunctional" transducer protein $\beta$-Arrestin has been shown by Abraham, et al. [20], to be essential to produce the length induced tension increase and small shift towards the cTn-C Ca ${ }^{2+}$ sensitivity through the angiotensin II type 1 receptor (AT1R). This is not via the G-protein phosphoinositide- $\mathrm{Ca}^{2+}$ second messenger system, i.e. there is no change in diastolic or systolic $\left[\mathrm{Ca}^{2+}\right]$ involved [15]. Protein phosphorylation [15] does though appear to be strongly involved as it is generally agreed that it is central to strength of contraction. In the case of MyBP-C and its functional insistence on $\mathrm{Mg}^{2+}-\mathrm{Ca}^{2+}$ exchange [6] one might expect the observed change in contraction on its PKA induced phosphorylation [21] but not in FSLH. Kinase action on the troponins does also modulate contraction strength [15], but again coupling with length induced changes has not been directly demonstrated and common PKA or PKC are not involved [1-4]. Downstream $\beta$-Arrestin stimulated $\mathrm{Ca}^{2+}$ independent phosphorylation has also been muted [20] but again not shown.

The one key observation by Abraham, et al. [20] is that Losartan, a drug that blocks AT1R activation, is found to block the length induced enhancement of cardiac sensitivity. So on length increase it would seem the AT1R is activated by an unknown mechanism, reflected in the losartan action. In any striated muscle when AT1R is activated the next step in the sequence is phosphorylation of the activated AT1R tail by adrenergic receptor kinase (GRK) [22,23], not PKA or PKC. This phosphorylation is followed by translocation of $\beta$-Arrestin from the cytoplasm to bind strongly to the phosphorylated AT1R at the plasma membrane (PM). This binding inhibits further phosphorylation of the AT1R. $\beta$-Arrestin is a kinase inhibitor. This is from where its name 
originates with discovery in the optic system [26,27]. Like a tiger no way does it change its spots with its location and activate phosphorylation.

\section{The binding of $\beta$-Arrestin to the angiotensin receptor, AT1R}

Recently there has been interest in this interaction. In their review Turu, et al. [28], indicate that besides the well-known G protein pathways AT1R also activates a parallel signalling pathway through $\beta$-arrestins. This $\beta$-arrestin mediated activation affects the phosphorylation of cytoplasmic proteins such as mitogen-activated protein kinase (MAPK). Gagnon, et al. [29] have approached the mechanism of interaction of the $\beta$-arrestins with the AT1R via mapping the interacting moieties of the ligand and receptor by cross bridging reactions. They site specifically introduced the unnatural amino acid (UAA) p-azido-L-phenylalanine (azF) into the intracellular loops (ICLs) and the C-tail of AT1R. UV-mediated photolysis of 25 different azF-labeled AT1Rs cross-linked $\beta$-arrestin to angiotensin activated AT1R. As expected from the strength of the binding they demonstrated the presence of numerous different interactions of the $\beta$-arrestin with the receptor.

\section{The effect of $\beta$-Arrestin translocation in muscle cells}

Myosin light chain-2 (MYL2) and its phosphorylation $[24,25,27,30,31]$ are central to the control of muscle contraction strength. MLCK activity would fit very well with the report by Zhang, et al. [14] of structural changes in the myosin heads on stretch activation. Generally in striated muscle MLCK is $\mathrm{Ca}^{2+}$ and calmodulin dependent but is also constitutively active, i.e. it has been found to have a variable fractions of its maximal activity in the absence of $\mathrm{Ca}^{2+}$ and calmodulin $[21,24,25]$. The variability probably arises with the level of self-phosphorylation reported. MLCK possibly has different substrate sensitivities when bound to $\mathrm{Ca} /$ calmodulin or not. It is associated in vivo with a calmodulin inhibitor of unknown function that possibly inhibits low level $\mathrm{Ca}^{2+} /$ Calmodulin activation thus preserving the suggested specificity of action. In the presence of Calmodulin it is specific for MYL2. Phosphorylation by MLCK of cTn-I has not been investigated. In the absence of AT1R activation MLCK is almost certainly partially inhibited by the kinase inhibitor $\beta$-arrestin that is normally present in the sarcoplasm, possibly binding the MYL2 bound MgADP-phosphomyosin [2,6,8,9]. One can envisage a MYL2 phosphorylation level maintained by MLCK and light chain phosphatase [32] (LCP) and also regulated by $\beta$-arrestin, a central point of control of contraction.

Reduction of $\beta$-arrestin inhibition of MLCK occurs on translocation of the $\beta$-arrestin from the cytoplasm to strongly bind to the AT1R on the PM on angiotensin activation. In diastolic length increase induced contraction strength, in FSLH, the essential phosphorylation of cardiac cTn-I on threonine 144 possibly also occurs this way, clearly not by normal PKA or PKC [1-4]. The increase in phosphorylation of MYL2 by MLCK increases the affinity of the MgADP- phosphomyosin for $\mathrm{Ca}^{2+}$ over that for $\mathrm{Mg}^{2+}$. The addition of more $\mathrm{Ca}^{2+}\left(\right.$ not $\left.\mathrm{Mg}^{2+}\right)$ chelating phosphate groups shifting the sensitivity to lower $\left[\mathrm{Ca}^{2+}\right]$ and increasing contractile strength. This is supplemented by Tn-I phosphorylation at residue 144, lowering its inhibitory role [15]. The myosin bound MgATP —MgADP-phosphomyosin equilibrium [8,9], which will be $\mathrm{pH}$ dependent, probably has a bearing in the inhibitory binding of $\beta$-arrestin to the (MYL2) [8,9], i.e. it appears phosphorylated.

\section{What is excluded in FSLH}

As with the specific essential phosphorylations above the amplitude of tension has been shown by de tombe, et al. [33], to be dependent on phosphorylation by PKA of both MyBP-C and cTn-I. Similar results were found with PKA phosphorylation of MyBP-C by Steltzer, et al. [34]. However, all or part of their results could also arise through the above mechanism by direct phosphorylation of the inactive AT1R by the cyclic AMP stimulated PKA addition. Distinguishing one kinase activation in the presence of all is not a trivial matter, however on stretch no evidence for common PKA or $\mathrm{C}$ activation or deactivation is evident [1-4]. The functions and role of MYL2 and its regulation in general muscle function are well reviewed [32,35,36], albeit various isoforms of the enzymes involved are present depending on type and muscle location.

\section{The future}

Clearly much work investigating the mechanism of length induced angiotensin receptor activation is needed. We also want to know if the specificity of the kinases mentioned here, MLCK and PKC-BII are altered by $\mathrm{Ca}^{2+} /$ calmodulin and autophosphorylation as is PKC-BII. The indications are that the small length induced increase of skeletal muscle contraction is down to MLC2 phosphorylation alone and the more pronounced in cardiac muscle down to the added concerted action of the threonine phosphorylation on residue 144 of cTn-I.

\section{References}

1. van der Velden J, de Jong JW, Owen VJ, Burton PB, Stienen GJ, Effect of protein kinase $A$ on calcium sensitivity of force and its sarcomere length dependence in human cardiomyocytes. Cardiovasc Res. 2000; 46: 487-495.

PubMed: https://www.ncbi.nlm.nih.gov/pubmed/10912459

2. Steinberg SF. Cardiac actions of protein kinase $\mathrm{C}$ isoforms. Physiology. 2012; 27: 130-139.

PubMed: https://www.ncbi.nlm.nih.gov/pubmed/22689788

3. Chandra M, Dong WJ, Pan BS, Cheung HC, Solaro RJ. Effects of Protein Kinase A Phosphorylation on Signaling between CardiacTroponin I and the N-Terminal Domain of Cardiac Troponin C. Biochemistry; 1997; 36: 13305-13311.

PubMed: https://www.ncbi.nlm.nih.gov/pubmed/9341222

4. Kobayashi T, Dong WJ, Burkart EM, Cheung HC, Solaro RJ. Effects of Protein Kinase C Dependent Phosphorylation and a Familial 
Hypertrophic Cardiomyopathy-Related Mutation of Cardiac Troponin I on Structural Transition of Troponin C and Myofilament Activation. Biochemistry. 2004; 43: 5996-6004.

PubMed: https://www.ncbi.nlm.nih.gov/pubmed/15147183

5. Smith GA. The Mechanisms of the Frank-Starling Law and Familial Cardiomyopathy are Different. The Function of Myosin Binding Protein-C is Retained on Myocyte Length Increase and Force Generated is Kinase controlled. OAT J Integr Cardiol. 2019; 5.

6. Smith GA. Calcium, Actomyosin Kinetics, Myosin Binding Protein-C and Hypertrophic Cardiomyopathy. OAT J Integr Cardiol. 2019; 5.

7. Solaro RJ, Shiner JS. Modulation of $\mathrm{Ca}^{2+}$ control of dog and rabbit cardiac myofibrils by $\mathrm{Mg}^{2+}$. Comparison with rabbit skeletal myofibrils. Circ Res. 1972; 39: 8-14.

PubMed: https://www.ncbi.nlm.nih.gov/pubmed/132310

8. Lionne $\mathrm{C}$, Brune M, Webb MR, Travers F, Barman T. Time resolved measurements show that phosphate release is the rate limiting step on myofibrillar ATPases. FEBS Letters. 1995; 364: 59-62. PubMed: https://www.ncbi.nlm.nih.gov/pubmed/7750544

9. Lymn RW, Taylor EW. Transient state phosphate production in the hydrolysis of nucleoside triphosphates by myosin. Biochemistry. 1970; 9: 2975-2983

PubMed: https://www.ncbi.nlm.nih.gov/pubmed/4248809

10. Pan BS, Solaro RJ. Calcium-binding properties of troponin-C in detergent skinned heart muscle fibers. J Biol Chem. 1987; 262: 7839-7849. PubMed: https://www.ncbi.nlm.nih.gov/pubmed/3584144

11. Morimoto $\mathrm{S}$, Ohtsuki I. $\mathrm{Ca}^{2+}$ binding to cardiac troponin-C in the myofilament lattice and its relation to myofibrillar ATPase activity. Eur J Biochem. 1994; 226: 597-602.

PubMed: https://www.ncbi.nlm.nih.gov/pubmed/8001574

12. Kampourakis $\mathrm{T} 1$, Yan Z1, Gautel M1, Sun YB1, Irving M. Myosin binding protein- $C$ activates thin filaments and inhibits thick filaments in heart muscle cells. Proc Natl Acad Sci U S A. 2014; 111: 18763-18768. PubMed: https://www.ncbi.nlm.nih.gov/pubmed/25512492

13. Hofmann PA, Hartzell HC, Moss RL. Alterations in $\mathrm{Ca}^{2+}$ sensitive tension due to partial extraction of C-protein from rat skinned cardiac myocytes and rabbit skeletal muscle fibers. J Gen Physiol. 1991; 97: 1141-1463.

PubMed: https://www.ncbi.nlm.nih.gov/pubmed/1678777

14. Zhang X, Kampourakis T, Yan Z, Sevrieva I, Irving M. et al. Distinct contributions of the thin and thick filaments to length-dependent activation in heart muscle. eLife. 2017; 6: e24081.

PubMed: https://www.ncbi.nlm.nih.gov/pubmed/28229860

15. de Tombe PP, Mateja RD, Tachampa K, Ait Mou Y, Farman GP, et al. Myofilament length dependent activation. J Mol Cell Cardiol. 2010; 48: 851-858.

PubMed: https://www.ncbi.nlm.nih.gov/pubmed/20053351

16. Akella AB, Su H, Sonnenblick EH, Rao VG, Gulati J. The Cardiac Troponin $\mathrm{C}$ Isoform and the Length Dependence of $\mathrm{Ca} 2+$ Sensitivity of Tension in Myocardium. J Mol Cell Cardiol. 1997; 29: 381-389.

PubMed: https://www.ncbi.nlm.nih.gov/pubmed/9040052

17. Tachampa K, Wang H, Farman GP, de Tombe PP. Cardiac Troponin I Threonine 144. Role in Myofilament Length-Dependent Activation. Circ Res. 2007; 101: 1081-1083.

PubMed: https://www.ncbi.nlm.nih.gov/pubmed/17975107

18. Wang H, Grant JE, Doede CM, Sadayappan S, Robbins J, et al. PKC- $\beta$ II sensitizes cardiac myofilaments to $\mathrm{Ca}^{2+}$ by phosphorylating troponin I on threonine-144. J Mol Cell Cardiol. 2006; 41: 823-833. PubMed: https://www.ncbi.nlm.nih.gov/pubmed/17010989
19. Blobe GC, Stribling DS, Fabbro D, Stabel S, Hannun YA. Protein Kinase C- $\beta$ II specifically binds to and is activated by F-actin. J Biol Chem. 1996; 271: 26: 15823-15830.

PubMed: https://www.ncbi.nlm.nih.gov/pubmed/8663149

20. Abraham DM, Davis RT, Warren CM, Mao L, Wolska BM. et al. $\beta$-Arrestin mediates the Frank-Starling mechanism of cardiac contractility. Proc Natl Acad Sci U S A. 2016; 113: 50: 14426-14431.

PubMed: https://www.ncbi.nlm.nih.gov/pubmed/27911784

21. Ponnam S, Sevrieva I, Sun YB, Irving M, Kampourakis T. Site-specific phosphorylation of myosin binding protein-C coordinates thin and thick filament activation in cardiac muscle. PNAS. 2019; 116: 15485-15494.

22. Ribas C, Penela P, Murga C, Salcedo A, García-Hoz C, et al. The G protein-coupled receptor kinase (GRK) interactome: Role of GRKs in GPCR regulation and signaling. Biochimica et Biophysica Acta (BBA) Biomembranes. 2007; 1768: 913-922.

23. Gurevich VV, Gurevich EV. GPCR Signaling Regulation: The Role of GRKs and Arrestins. Frontiers in Pharmacology. 2019; 10: 125 PubMed: https://www.ncbi.nlm.nih.gov/pmc/articles/PMC6389790/

24. Wolf $\mathrm{H}$, Hofmann F. Purification of myosin light chain kinase from bovine cardiac muscle. Proc Natl Acad Sci U S A. 1980; 77: 5852-5855. PubMed: https://www.ncbi.nlm.nih.gov/pubmed/6934518

25. Walsh MP, Vallet B, Autric F, Demaille JG. Purification and Characterization of Bovine Cardiac Calmodulin dependent Myosin Light Chain Kinase. J Biol Chem. 1979; 254: 12136-12144.

PubMed: https://www.ncbi.nlm.nih.gov/pubmed/500701

26. Wilden $U$, Hall SW, Kühn $H$. Phosphodiesterase activation by photoexcited rhodopsin is quenched when rhodopsin is phosphorylated and binds the intrinsic 48-kDa protein of rod outer segments. Proc Natl Acad Sci U S A. 1986; 83: 1174-1178.

PubMed: https://www.ncbi.nlm.nih.gov/pubmed/3006038

27. Wilden $U$, Wüst $E$, Weyand $I, K u ̈ h n ~ H$. Rapid affinity purification of retinal arrestin (48 $\mathrm{kDa}$ protein) via its light-dependent binding to phosphorylated rhodopsin. FEBS Lett. 1986; 207: 292-295. PubMed: https://www.ncbi.nlm.nih.gov/pubmed/3770202

28. Turu G, Balla A, Hunyady L. The Role of b-Arrestin Proteins in Organization of Signaling and Regulation of the AT1 Angiotensin Receptor. Front Endocrinol (Lausanne). 2019; 10: 519. PubMed: https://www.ncbi.nlm.nih.gov/pubmed/31447777

29. Gagnon L, Yubo Cao Y, Cho A, Sedki D, Huber T, et al. Genetic code expansion and photocross-linking identify different $\beta$-arrestin binding modes to the angiotensin II type 1 receptor. J Biol Chem. 2019; 294; 17409-17420.

30. Ishikawa Y, Kurotani R. Cardiac Myosin Light Chain Kinase, A New Player in the Regulation of Myosin Light Chain in the Heart. Circ Res. 2008; 102: 516-518.

PubMed: https://www.ncbi.nlm.nih.gov/pubmed/18340016

31. Stelzer JE, Patel JR, Moss RL. Acceleration of stretch activation in murine myocardium due to phosphorylation of myosin regulatory light chain. J Gen Physiol. 2006; 128: 261-272. PubMed: https://www.ncbi.nlm.nih.gov/pubmed/16908724

32. Chang AN, Kamm KE, Stull JT. Role of myosin light chain phosphatase in cardiac physiology and pathophysiology. J Mol Cell Cardiol. 2016; 101: $35-43$

PubMed: https://www.ncbi.nlm.nih.gov/pmc/articles/PMC5154923/

33. Kumar M, Govindan S, Zhang M, Khairallah RJ, Martin JL, et al. Cardiac myosin-binding protein $\mathrm{C}$ and troponin-I phosphorylation independently modulate myofilament length-dependent activation. J Biol Chem. 2015 
290: 29241-29249.

PubMed: https://www.ncbi.nlm.nih.gov/pubmed/26453301

34. Mamidi R, Gresham KS, Verma S, Stelzer JE. Cardiac Myosin Binding Protein-C Phosphorylation Modulates Myofilament Length-Dependent Activation. Front Physiol. 2016; 7: Article 38.

PubMed: https://www.ncbi.nlm.nih.gov/pmc/articles/PMC4753332/

35. Sheikh F, Lyon RC, Chen J. Functions of myosin light chain-2 (MYL2) in cardiac muscle and disease. Gene. 2015; 569: 14-20.

PubMed: https://www.ncbi.nlm.nih.gov/pubmed/26074085

36. Ding P, Huang J, Battiprolu PK, Hill JA, Kamm KE, et al. Cardiac Myosin Light Chain Kinase Is Necessary for Myosin Regulatory Light Chain Phosphorylation and Cardiac Performance in Vivo. J Biol Chem. 2010; 285: 40819-40829.

PubMed: https://www.ncbi.nlm.nih.gov/pmc/articles/PMC3003383/ 